Extended abstract submitted for presentation at the AIAA $42^{\text {nd }}$ Aerospace Sciences Meeting, Reno, NV, January 5-8, 2004

\title{
Thermal Characteristics and Structure of Fully-Modulated, Turbulent Diffusion Flames in Microgravity
}

\author{
J.C. Hermanson \\ University of Washington, Seattle, WA 98195 \\ H. Johari \\ Worcester Polytechnic Institute, Worcester MA 01609 \\ D.P. Stocker and U. G. Hegde \\ NASA Glenn Research Center, Cleveland, OH 44135
}

\section{SUMMARY}

Turbulent jet diffusion flames are studied in microgravity and normal gravity under fullymodulated conditions for a range of injection times and a $50 \%$ duty cycle. Diluted ethylene was injected through a 2-mm nozzle at a Reynolds number of 5,000 into an open duct, with a slow oxidizer co-flow. Microgravity tests are conducted in NASA's 2.2 Second Drop Tower. Flames with short injection times and high duty cycle exhibit a marked increase in the ensemble-averaged flame length due to the removal of buoyancy. For other injection conditions, including steady-state injection, the flame length is not strongly impacted by buoyancy. The cycle-averaged centerline temperature profile reveals higher temperatures in the microgravity flames, especially at the flame tip where the difference is about $200 \mathrm{~K}$. In addition, the cycle-averaged measurements of flame radiation were about $30 \%$ to $60 \%$ greater in microgravity than in normal gravity.

\section{INTRODUCTION}

Unsteady combustion appears to have the potential to provide for rapid fuel/air mixing, compact and economical combustors, and reduced exhaust emissions. The objective of this experiment is to increase the fundamental understanding of the fuel/air mixing and combustion behavior of pulsed, turbulent diffusion flames by conducting experiments in microgravity. In this research the fuel jet is fully-modulated (i.e., completely shut off between pulses) by an externally controlled valve system. This gives rise to drastic modification of the combustion and flow characteristics of flames,[1-2] leading to enhanced fuel/air mixing compared to acoustically excited or partially-modulated jets. The technique simplifies the combustion process by avoiding the acoustic forcing generally present in pulsed combustors. Fundamental issues addressed in this experiment include the impact of buoyancy on the structure and flame length, temperatures, and radiation of fully-modulated flames.

\section{EXPERIMENTAL APPROACH}

Experiments are conducted both in the laboratory at WPI and in the GRC 2.2s Drop Tower. The combustor configuration consists of a single fuel nozzle with diameter $d=2 \mathrm{~mm}$ centered in a combustor $20 \times 20 \mathrm{~cm}$ in cross section and $67 \mathrm{~cm}$ in height. The gaseous fuel jet flow (ethylene or a 50/50 ethylene/nitrogen mixture by volume) is fully-modulated by a fast-response solenoid valve actuated in an on-off (rectangular wave) fashion for injection times ranging from $\tau=4$ to $\tau$ $=300 \mathrm{~ms}$. The mean fuel velocity during injection, $U_{j e t}$, gives a nominal Reynolds number of

This is a preprint or reprint of a paper intended for presentation at a conference. Because changes may be made before formal publication, this is made available with the understanding that it will not be cited or reproduced without the permission of the author. 
5,000. A slow oxidizer co-flow with velocity of approximately $10 \mathrm{~cm} / \mathrm{s}$ (air for laboratory experiments; an oxygen/nitrogen mixture of either $21 \%$ or $30 \% \mathrm{O}_{2}$ by volume for the Drop Tower rig) is provided to properly ventilate the flame.[3] An electrically heated wire loop of $0.24 \mathrm{~mm}$ diameter situated at the nozzle exit serves as a continuous ignition source.

Three types of diagnostic techniques are employed in the experiments. Video imaging is used to study the turbulent structure and flame length of the pulsed flames. Temperatures and radiant emissions are determined using fine-wire thermocouples and thermopile radiometers.

\section{RESULTS}

\section{Structure and flame length}

The fully-modulated flames can be roughly divided into two categories: (i) injection time sufficiently short to result in a compact, puff-like structure, and (ii) injection interval longer, resulting in elongated flame structures. The parameter $P \equiv\left(U_{j e t} \tau / d\right)^{1 / 3}$ can be employed to distinguish between the two cases.[1] Generally, puff-like behavior is seen for values of $P$ less than approximately $P=8$ for ethylene/air flames. For $P>11$, elongated flames similar to steady jet flames but with a distinct cap are created.[1,3] Typical images of steady, elongated, and pufflike ethylene/air diffusion flames in microgravity are presented in Fig. 1.

The flame lengths of fully-modulated diffusion flames can be substantially less that those of steady turbulent jet flames, as shown in Fig. 2 . In all cases shown the duty cycle was sufficiently low to give isolated, non-interacting flame structures. The flame length for compact, puff-like structures appears to scale reasonably well with the parameter[2] $P(1+\psi)^{1 / 3}$, where $\psi$ is the stoichiometric air/fuel ratio, up to values consistent with $P \approx 8$. For sufficiently high $P$, the mean flame length approaches that of the corresponding steady flame. The flame length interestingly does not appear to be highly sensitive to the action of buoyancy for all $P$. This is consistent with the results of Ichideria et al.[4] for piloted flames, but differs from the significant increase in length reported by Hegde et al.[5] in microgravity for unpiloted flames stabilized by reduced nozzle clearance.

The flame length in fully-modulated diffusion flames can also be significantly impacted by the duty cycle, as shown in Fig. 3. In general, increasing the duty cycle causes the discrete fuel puffs to give way to more closely-packed, interacting flame structures, which lead in turn to a longer flame length. This is to be expected since for the case of high duty cycles each flame structure has to "compete" with its neighbors for the same air, decreasing the rate of air entrainment. The greatest fractional increase in flame length appears to be for the shortest injection time, as seen previously in normal gravity[1]. This suggests a substantially lower impact of neighboring structures on the rate of entrainment and mixing for elongated flames than for their puff-like counterparts. For microgravity conditions the increase in flame length with increasing duty cycle can significantly exceed that seen in normal gravity.

The celerity for flame puffs near burn-out, taken from the slope of the puff trajectory versus time, is generally less in microgravity than in normal gravity. This is consistent with the longer time to burn-out observed for microgravity flame puffs. These two effects appear to be offsetting, with the result that the flame length of isolated, compact puffs is insensitive to buoyancy.

The combination of increasing flame puff size and decreasing puff celerity with downstream distance serves to change the separation between puffs, effectively increasing the duty cycle locally. The amount by which the duty cycle near the flame tip exceeds the injection duty cycle is greater in microgravity than in normal gravity due to the lower celerity in the former case, suggesting that the change in flame length with increasing injection duty cycle would be 
correspondingly greater in microgravity. This is in qualitative agreement with the experiments.

Varying the duty cycle allows for the systematic examination of the interaction and merging of the large structures, especially for the case of slowed flame motion in microgravity. An example of a microgravity flame at a duty cycle sufficiently high to result in significant structurestructure interaction is shown in Fig. 4, where the merging of discrete flame structures is shown.

\section{Thermal characteristics}

Buoyancy appears to have a strong effect on the thermal characteristics of fully-modulated turbulent diffusion flames.[6] The cycle-averaged centerline temperatures are generally higher in the microgravity flames than in normal gravity, especially at the flame tip where the difference was as much as $200 \mathrm{~K}$. This is shown in Fig. 5 for $P=12$ and $\alpha=0.5$. The flame is 50/50 ethylene/nitrogen in $21 / 29$ oxygen/nitrogen $(\psi=7.1)$. It can be seen that centerline temperature is higher in microgravity than in normal gravity throughout the length of the flame. The cycleaveraged thermal radiation appears to be more strongly influenced by gravity than the temperature, and can be as much as $60 \%$ greater in microgravity than in normal gravity.

Elevated values of temperature and radiation intensity are also found for other values of $P$. The peak values of cycle-averaged centerline temperature are roughly $80 \mathrm{~K}$ greater in microgravity for all values of $P$. The peak radiation was about $30 \%$ to $60 \%$ greater in microgravity than normal gravity. The peak temperature appears to decrease, then to become roughly constant as $P$ is increased, with the transition occurring at $P \approx 8$ (a similar value as that for the transition in flame length mentioned previously). By contrast, the radiation increases with $P$, and appears to level off at sufficiently high $P$ in a similar fashion to the flame length.

Additional thermal measurements will be presented and discussed in the final paper.

\section{REFERENCES}

[1] Hermanson, J.C., Dugnani, R., and Johari, H., Comb. Sci. Tech. 155, 203-225, 2000.

[2] Johari, H. and Motevalli, V., Comb. Sci. Tech. 94 (1-6), 229-245, 1993.

[3] Hermanson, J.C., Usowicz, J., Johari, H., and Sangras, R., AIAA Journal 40 (7), 2002.

[4] Idicheria, C.A., Boxx, I.G., and Clemens, N.T., AIAA 2001-0628, Reno, NV, Jan. 2001.

[5] Hegde, U., Zhou, L., and Bahadori, M.Y., Comb. Sci. Tech. 102, 95-113, 1994.

[6] Page, K.L., Stocker, D.P, Hegde, U.G., Hermanson, J.C. and Johari, H., Third Joint Meeting of the U.S. Sections of The Combustion Institute, Chicago, IL, March, 2003.

[7] Johari, H., Ghaem-Maghami, E., and Hermanson, J.C., AIAA 03-1015, Reno, NV, Jan. 2003. 

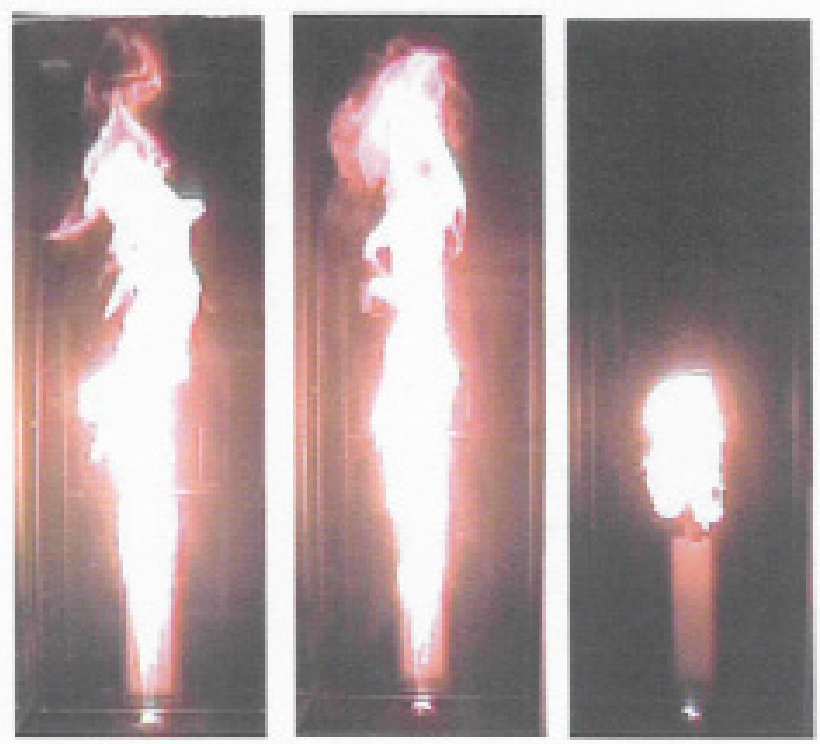

Fig. 1 Turbulent ethylene/ $\left(30 \% \mathrm{O}_{2}\right.$ in $\left.\mathrm{N}_{2}\right)$ diffusion flames in microgravity. Left, steady flame, middle, fully-modulated flame with $\tau=300 \mathrm{~ms}, P=15$, right, $\tau=40 \mathrm{~ms}, P=7.7$.

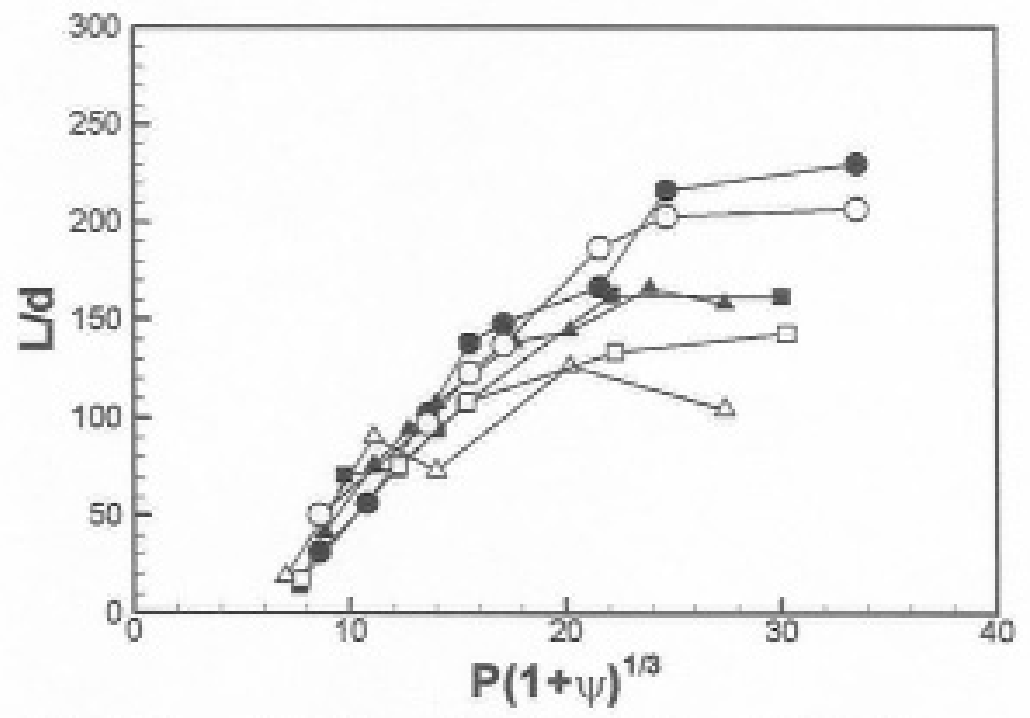

Fig. 2 Normalized flame length for fully-modulated flames. Solid symbols, microgravity; open symbols, normal gravity. $\bigcirc$, - $\psi=10 ; \mathbf{\square}, \square \psi=7.1, \Delta, \boldsymbol{\Delta} \psi=5$. 


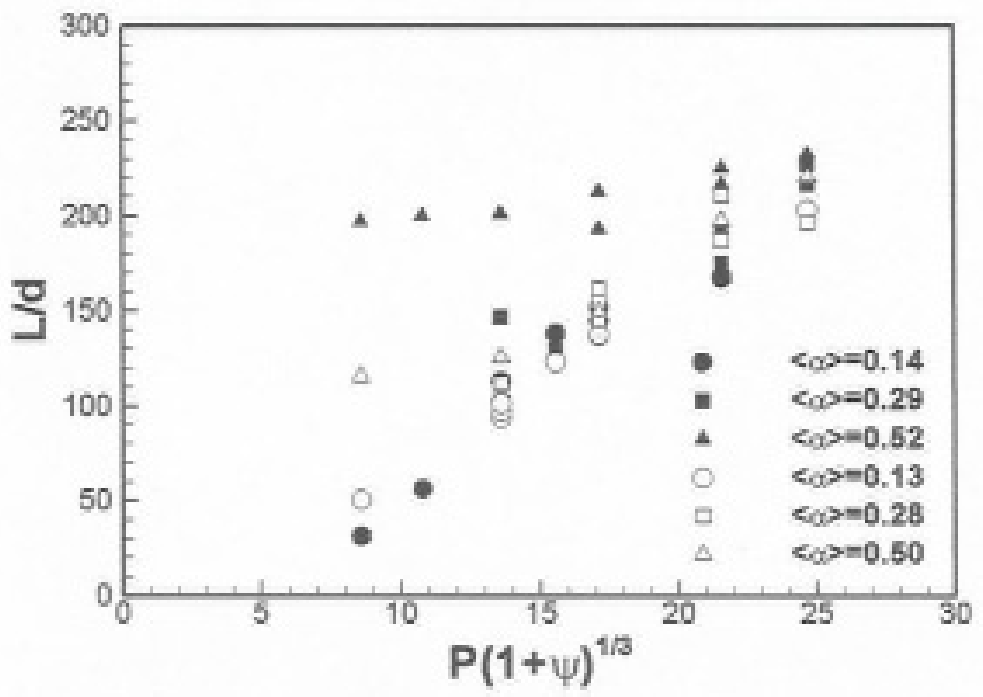

Fig. 3 Effect of injection duty cycle on normalized flame length for fully-modulated flames for $\psi=10$. Solid symbols, microgravity; open symbols, normal gravity.

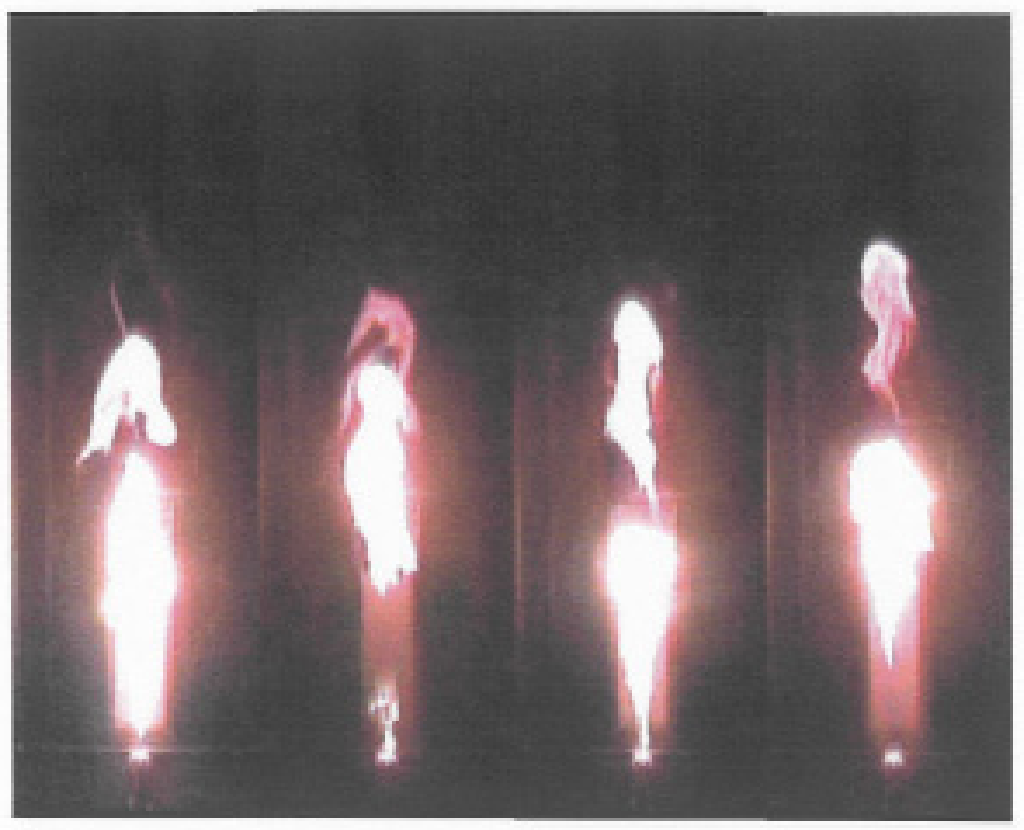

Fig. 4 Sequence of fully-modulated flames in microgravity showing the merging of large-scale turbulent structures. $P=7.6$, $\alpha=0.5$. 


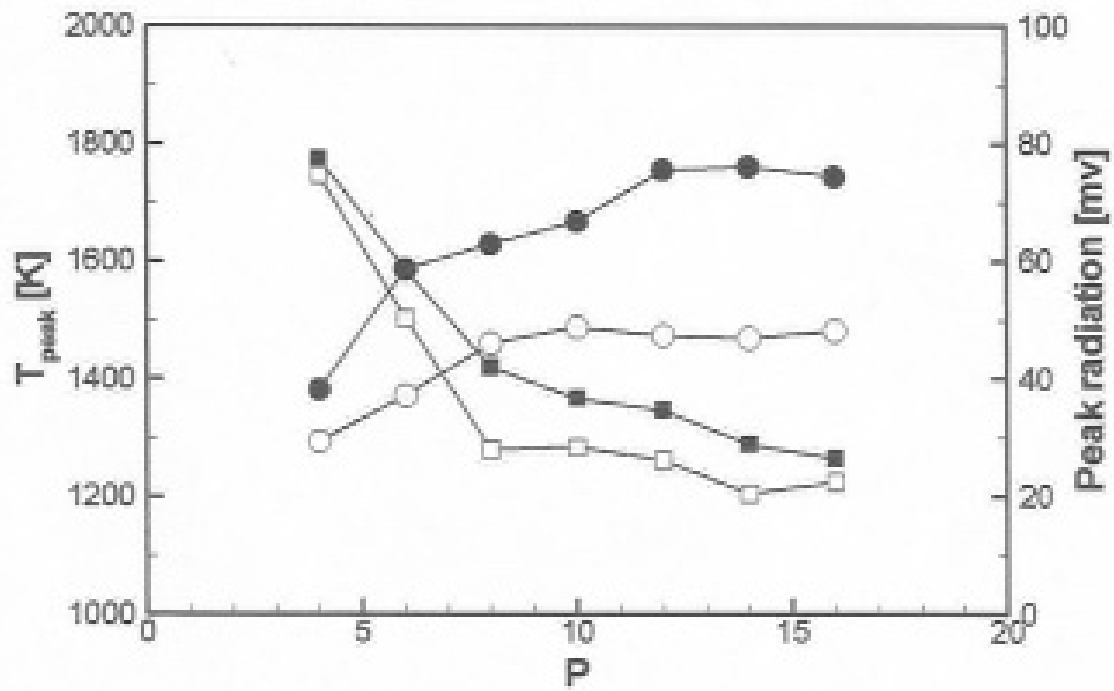

Fig. 5 Mean centerline temperatures and radiation for a $P=8$ fullymodulated flame. Solid symbols, microgravity; open symbols, normal gravity. $\bigcirc$, $\odot$ radiation; $\mathbf{\square}, \square$ temperature. 